\title{
Some studies on shape memory alloy friction spun yarn
}

\begin{abstract}
This paper reports on the utilization of Shape Memory Alloy (SMA) wire as a conductive element in core-sheath friction yarn. The yarns were spun using DREF 3000 spinning machine. The yarn consisted of three layers with the SMA wire at the core and $100 \%$ cotton fibers at the second layer and as the sheath producing a yarn called SMA Friction Spun Yarn (SMA FSY). Three different core-sheath ratios and spinning drum speeds were used in the spinning process. The objectives were to compare the SMA FSY yarn tensile properties and to understand the influence of the machine process parameters towards the actuating performance under stress-free condition. Results showed that the SMA FSY with $60 \%$ core and highest spinning drum speed gave better tensile strength. Additionally, this yarn also gave the fastest initiating deformation below 100 seconds. It can be concluded that the changes in the machine process parameters influenced the tensile and actuating performance of SMA FSY.
\end{abstract}

Keyword: Friction spinning; Core-sheath yarn; Shape memory alloy 